\title{
Interpreting Umbilical Cord Blood Gases Cord Occlusion with Terminal Fetal Bradycardia: Part IV
}

Jeffrey Pomerance, $M D, M P H$

\section{Case 13: Cord Occlusion with Single Cord Gas Result}

The mother was a 35-year-old, gravida 2, para 0, aborta 1 with an intrauterine pregnancy at $384 / 7$ weeks gestation. NSTs during the week prior to delivery were reactive. The initial FHR was 150-160 bpm with moderate beat-to-beat variability. Recurrent deeper and longer-lasting variable decelerations and prolonged decelerations ensued. Terminally, the FHR was approximately $60 \mathrm{bpm}$ with poor variability. The tracing ended 13 minutes before delivery and 20 minutes after the beginning of the severe fetal bradycardia.

"Recurrent deeper and longer-lasting variable decelerations and prolonged decelerations ensued. Terminally, the FHR was approximately $60 \mathrm{bpm}$ with poor variability. The tracing ended 13 minutes before delivery and 20 minutes after the beginning of the severe fetal bradycardia."

An emergency cesarean delivery under epidural and general anesthesia resulted in an infant with Apgar scores of 0 and 3 at one and five minutes, respectively. Intubation, cardiac compressions, and ETT epinephrine were provided. Birth weight was $3120 \mathrm{~g}$.

An umbilical arterial cord blood gas result was as follows:

\begin{tabular}{|c|c|c|}
\hline & Umbilical Vein & Umbilical Artery \\
\hline $\mathrm{pH}$ & NA & 7.26 \\
\hline $\mathrm{PcO}_{2} \underset{(\mathrm{kPa})}{(\mathrm{mmHg})}$ & NA & $\begin{array}{l}45 \\
6.00\end{array}$ \\
\hline $\begin{array}{ll}\mathrm{Po}_{2} & (\mathrm{mmHg}) \\
(\mathrm{kPa}) & \end{array}$ & NA & $\begin{array}{l}41 \\
5.47\end{array}$ \\
\hline BD (mmol/L) & NA & 7 \\
\hline
\end{tabular}

Twenty cc of normal saline were given via a UVC at age 10 minutes.

A subsequent arterial blood gas at age 18 minutes was as follows:

\begin{tabular}{|c|c|}
\hline & $A B G$ \\
\hline $\mathrm{pH}$ & 6.84 \\
\hline $\mathrm{Pco}_{2} \underset{(k P a)}{(\mathrm{mmHg})}$ & $\begin{array}{l}61 \\
8.13\end{array}$ \\
\hline $\begin{array}{ll}\mathrm{Po}_{2} & \underset{(\mathrm{kPa})}{(\mathrm{mmHg})}\end{array}$ & $\begin{array}{l}118 \\
15.73\end{array}$ \\
\hline $\mathrm{BD}$ (mmol/L) & 23 \\
\hline
\end{tabular}

The initial hematocrit was $54 \%$. Blood culture was negative. At age two days, a head ultrasound showed increased echogenicity in the thalami. At six days of age, an MRI of the head demonstrated thalamic injury. At age ten months, a diagnosis of hypotonic cerebral palsy was made.

\section{Interpretation}

The sample identified as arterial has a normal $\mathrm{pH}, \mathrm{PcO}_{2}$, and base deficit. The $\mathrm{PO}_{2}$ is way above the upper end of normal. In a newborn with a one-minute Apgar score of 0 , even an umbilical arterial $\mathrm{PO}_{2}$ above the normal mean of $18 \mathrm{mmHg}$ would be unlikely. This blood gas cannot possibly reflect the arterial blood gas status at birth of this apparently lifeless infant. If the infant is depressed at birth, a $\mathrm{PO}_{2}$ above the arterial mean suggests the sample came from the umbilical vein. Therefore, the sample obtained is almost certainly venous, not arterial. To quote a famous sports personality and commentator, Charles Barkley,() (1) "I may be wrong, but I doubt it."

\section{"The question then becomes: approximately what would the umbilical arterial sample values have been had they been obtained? It is helpful to take this in small steps. Would they have been essentially normal or abnormal?"}

Corrected vessel identification appears below. 


\begin{tabular}{|c|c|c|}
\hline & Umbilical Vein & Umbilical Artery \\
\hline $\mathrm{pH}$ & 7.26 & NA \\
\hline $\mathrm{PcO}_{2} \underset{(\mathrm{kPa})}{(\mathrm{mmHg})}$ & $\begin{array}{l}45 \\
6.00\end{array}$ & NA \\
\hline $\begin{array}{ll}\mathrm{Po}_{2} & (\mathrm{mmHg}) \\
(\mathrm{kPa})\end{array}$ & $\begin{array}{l}41 \\
5.47\end{array}$ & NA \\
\hline $\mathrm{BD}(\mathrm{mmol} / \mathrm{L})$ & 7 & NA \\
\hline
\end{tabular}

The question then becomes: approximately what would the umbilical arterial sample values have been had they been obtained? It is helpful to take this in small steps. Would they have been essentially normal or abnormal? Certainly, one would not expect to find normal umbilical arterial sample results following a 20 minute severe, terminal bradycardia along with a one-minute Apgar score of 0 . The next question becomes: would one expect the umbilical arterial sample to be mildly abnormal or severely abnormal? With a one-minute Apgar score of 0 and a follow-up arterial blood gas base deficit of 23 at 18 minutes of age, even with an expected acid washout, one would anticipate an umbilical cord arterial base deficit in the high teens to $20 \mathrm{mmol} / \mathrm{L}$. This clearly suggests the etiology to be umbilical cord occlusion. A history of recurrent deep variable decelerations lasting 60-90 seconds and prolonged decelerations also suggests cord occlusion. An umbilical venous $\mathrm{PO}_{2}$ at the upper end of normal suggests a brief period of time when the umbilical venous blood flow was slowed but not entirely stopped prior to a complete cessation of blood flow in this vessel. Slowed blood flow allows for a more efficient transfer of carbon dioxide to the mother and oxygen to the fetus. Since the umbilical cord was not entangled around any fetal structure, nor was a prolapsed cord identified, the most likely diagnosis becomes occult cord occlusion/prolapse.

Obtaining an umbilical cord arterial blood gas sample is always harder than obtaining a venous sample as the vein is so much larger. Spanning four years and including over 19,000 deliveries, at a center in which a routine attempt was made to obtain paired umbilical cord blood gas samples at all deliveries, paired-samples were successfully obtained about 64 percent of the time. () (2) One cause of the difficulty in obtaining arterial blood stems from the net transfer of blood into the placenta when the umbilical vein, but not the artery, is compressed. The resultant fetal/neonatal hypovolemia is likely to make obtaining an arterial umbilical cord blood gas sample even more difficult. There is less blood than normal in the umbilical arteries.

Myers (3) found that total cord occlusion resulted in an increasing base deficit of $1.1 \mathrm{mmol} / \mathrm{L} /$ minute. However, Myers's model acutely and completely shut off blood flow in both the umbilical vein and arteries. Early in the phase of cord occlusion with terminal fetal bradycardia, generally, there is a period when the vein remains occluded, but umbilical arterial blood flow resumes, resulting in fetal hypovolemia. Hypovolemia in conjunction with hypoxia likely results in a more rapid onset of poor blood flow to the heart and brain, i.e., ischemia. Therefore, increasing base deficit, or metabolic acidosis, may accumulate more rapidly than $1.1 \mathrm{mmol} / \mathrm{L} /$ minute. Ischemia is a much more potent cause of hypoxic-ischemic-encephalopathy than is hypoxia alone. () (4) This explains the surprisingly large base deficit of 27 following 20 minutes of cord occlusion. A normal hematocrit of $54 \%$, despite likely significant net transfer of blood to the placenta during the terminal bradycardia, does not argue against this transfer as the normal range of newborn hematocrits at the time of birth is quite wide, $42 \%-65 \%$.() (5) Most likely, the greater the difference between the umbilical vein and umbilical artery blood gases, the greater the degree of fetal/neonatal hypovolemia.

In many situations, although the umbilical cord blood gas sample is mislabeled and only a single sample is drawn, it may be possible to approximate at least part of the missing data.

\section{$\underline{\text { Key Points }}$}

- Unless both umbilical venous and umbilical arterial samples are obtained, one cannot be certain that a single sample is from an umbilical artery, even if it is so labeled.

- If the infant is severely depressed at birth, a $\mathrm{Po}_{2}$ above the arterial mean suggests the sample came from the umbilical vein.

- Obtaining an umbilical cord arterial blood gas sample is always harder than obtaining a venous sample as the vein is so much larger. Following a period of cord occlusion with terminal fetal bradycardia, during which there is a net transfer of blood to the placenta, the resultant fetal/ neonatal hypovolemia adds to the difficulty of obtaining an umbilical arterial cord blood gas sample. There is simply less blood than normal in the umbilical arteries.

- Metabolic acidosis may accumulate more rapidly in the presence of both hypoxia and hypovolemia than with hypoxia alone.

- Most likely, the greater the difference between the umbilical vein and artery blood gases, the greater the degree of fetal/neonatal hypovolemia.

\section{Case 14: Cord Occlusion without Widened Venoarterial Cord Gas Differences}

The mother was a 38-year-old, obese, gravida 2, para 0, aborta 1 , with an intrauterine pregnancy of $391 / 7$ weeks' gestation. Fetal movement was present; the fetal monitor demonstrated moderate variability and there were accelerations. At times, it was difficult to monitor FHR. Membranes were artificially ruptured 11 hours prior to delivery with egress of clear fluid. The cervix was completely dilated and effaced eight hours prior to delivery. The fetus was manually turned from occiput posterior (OP) to occiput anterior $(\mathrm{OA})$ twice in the three hour period prior to delivery. Both times the fetus reverted to OP. Just following a decision for cesarean delivery, approximately one hour prior to delivery, there were multiple variable decelerations lasting 30-60 seconds and the FHR baseline was rising. During the final 40 minutes prior to delivery, the FHR was unmonitored. Just prior to placement 
of spinal anesthesia, the FHR was auscultated at $151 \mathrm{bpm}$. The mother's recent heart rate was quite similar. At delivery, it was difficult to elevate the fetal head out of the pelvis. After 30 seconds of pushing from below, the fetal head was elevated into the uterus.

Various versions of the Apgar scores appeared in the record. There was agreement that the Apgar scores were 0 until age 10 minutes when the score was 1 . There was further agreement that the score was never higher than 1 through age 25 minutes. At age 30 minutes, the Apgar score was either 1 or 4 ; and at 35 minutes, was again recorded as 1 . At age 40 minutes, the Apgar score was recorded as 6 , but there was no breakdown of the components. Resuscitation included: bag/mask ventilation, intubation, PPV with $100 \%$ oxygen, chest compressions, epinephrine via ETT and UVC, and UVC normal saline and bicarbonate. During all of the resuscitation, there was no record that the infant was ever reintubated. Therefore, the endotracheal tube was almost certainly in the trachea.

Cord blood gas results were as follows:

\begin{tabular}{|c|c|c|}
\hline & Umbilical Vein & Umbilical Artery \\
\hline $\mathrm{pH}$ & 7.255 & 7.162 \\
\hline $\mathrm{PcO}_{2} \underset{(\mathrm{kPa})}{(\mathrm{mmHg})}$ & $\begin{array}{l}48 \\
6.40\end{array}$ & $\begin{array}{l}67 \\
8.93\end{array}$ \\
\hline $\begin{array}{c}\mathrm{Po}_{2} \\
(\mathrm{kPa})\end{array}$ & $\begin{array}{l}25 \\
3.33\end{array}$ & $\begin{array}{l}9 \\
1.20\end{array}$ \\
\hline BD (mmol/L) & 6 & 5 \\
\hline
\end{tabular}

A follow-up $A B G$ at age 34 minutes was:

\begin{tabular}{|c|c|}
\hline & Infant's ABG \\
\hline $\mathrm{pH}$ & 6.97 \\
\hline $\mathrm{PcO}_{2} \underset{(\mathrm{kPa})}{(\mathrm{mmHg})}$ & $\begin{array}{l}27 \\
3.60\end{array}$ \\
\hline $\begin{array}{ll}\mathrm{Po}_{2} & \underset{(\mathrm{kPa})}{(\mathrm{mmH})}\end{array}$ & $\begin{array}{l}437 \\
58.27\end{array}$ \\
\hline $\mathrm{BD}$ (mmol/L) & 26 \\
\hline
\end{tabular}

A UVC hematocrit obtained at age two hours was $45 \%$. Blood culture was negative. Head ultrasound at age three hours was normal. An MRI of the brain at age 29 hours showed infarction in the watershed areas of both occipital lobes and in both basal ganglia. Findings were consistent with acute total asphyxia. Also observed were a small subarachnoid hemorrhage, a small subdural hematoma (without evidence of mass effect), and an occipital subgaleal hemorrhage.

The infant demonstrated early seizures, HIE, DIC, and renal, hepatic, and cardiac dysfunction. At age 16 months, this child exhibited severe developmental delay, variable muscle tone, dystonia and athetosis, and mild spasticity, more evident in the lower extremities.

\section{Interpretation}

The umbilical venous blood gas is entirely normal. The umbilical arterial blood $\mathrm{pH}$ is slightly low, the $\mathrm{PCO}_{2}$ is mildly elevated, and the $\mathrm{PO}_{2}$ and base deficit are normal, i.e., there is a mild respiratory acidosis. The difference between the umbilical venous and arterial $\mathrm{pH}$ is at the upper end of normal $(6,7)(7.255-7.162=0.093$; the $\mathrm{pH}$ values were reported to a third decimal place so that this calculation would be clearer). Therefore, this in and of itself is not suggestive of cord occlusion. However, there are considerable associated data that do suggest cord occlusion with terminal bradycardia.

First, the fetus was twice rotated from OP to OA. This requires elevating the head out of the pelvis, thus providing an opportunity for the cord to migrate to a position alongside the head. $(8,9)$ Second, just prior to the end of FHR monitoring, moderate variable decelerations were present, suggesting that the umbilical cord was in a vulnerable position. Third, there was a 40 minute period of no fetal monitoring. Fourth, a heart rate of $151 \mathrm{bpm}$ was auscultated just prior to placement of spinal anesthesia (a rate very close to the maternal heart rate). And finally, and perhaps most importantly, at birth, the infant had no signs of life. And yet, the cord gases were near normal. Which should one believe ... the near-normal umbilical cord blood gases or one's own lying eyes? One should believe both! Clearly, one must believe that this infant had no heart rate at birth. A normal set of cord gases associated with a severely depressed newborn infant suggests cord occlusion with terminal fetal bradycardia. Considerable umbilical venoarterial $\mathrm{pH}$ differences almost always accompany cord occlusion with terminal bradycardia, but if there is little or no resumption of umbilical arterial blood flow, the $\mathrm{pH}$ difference will not be widened.

Because the resuscitation was so difficult, it is unlikely that the fetal heart rate dropped to near-zero in the preceding few minutes. On the other hand, it is also unlikely that the FHR stopped 40 minutes earlier because if this were so, this infant would have been dead. As it was, this infant was very nearly unresuscitable. In all likelihood, therefore, there was severe fetal bradycardia for at least 20 minutes prior to delivery.

Optimally, to confidently establish a diagnosis of cord compression as the etiology of severe neonatal depression without associated widened $\mathrm{pH}$ differences, one would like to see a regularly improving condition of the newborn beginning at birth, followed by documentation of severe metabolic acidosis within the first hour (as soon as possible) following birth. As there is almost always a widening of the normal venoarterial $\mathrm{pH}$ difference associated with cord occlusion and terminal bradycardia, when there is not, other findings must be carefully sought (see Table below). In this 
case, the great difficulty in the initial resuscitation undoubtedly contributed to the very severe metabolic acidosis found at 34 minutes of age. Because of the results of the ABG at that time (low $\mathrm{PCO}_{2}$ and very high $\mathrm{PO}_{2}$ ), it would appear that an Apgar score of 4 at age 30 minutes was more likely than an Apgar score of 1.

This was only the second case in which I thought there was cord compression with terminal fetal bradycardia as the etiology of neonatal depression in the absence of widened umbilical venoarterial $\mathrm{pH}$ differences. I have seen about half a dozen more since. However, as is pointed out in Case 9 (virtual cord occlusion), theoretically, umbilical $\mathrm{pH}$ differences do not have to be widened. This case suggests that the umbilical vein and arteries were all permanently occluded simultaneously, or almost simultaneously, at the onset of the terminal fetal bradycardia. This infant's head was tightly wedged into the pelvis and was difficult to extract, making it likely that the umbilical cord was also forcefully occluded. Therefore, one would not expect neonatal hypovolemia in this infant. The initial hematocrit was at the lower end of normal(4) (4), but there was some blood loss into the head as documented by the small subarachnoid, subdural, and subgaleal hemorrhages.

Discontinuing resuscitative efforts might have been considered during the very long and difficult resuscitative effort in this infant. A future case will discuss this issue further.

\section{Cord Occlusion with Terminal Fetal}

Bradycardia and Normal or Near Normal Cord Gases in the absence of Widened Umbilical

Venoarterial Differences

\begin{tabular}{|l|l|}
\hline Findings & $\begin{array}{l}\text { 1 min Apgar } \\
\text { Score } \geq 1\end{array}$ \\
\hline Moderate or Severe Variable Decelerations and/or & Yes \\
\hline Cord Tightly Around Fetal Body Part or & Yes \\
\hline Occult or Overt Cord Prolapse or & Yes \\
\hline Shoulder Dystocia or & Yes \\
\hline Breech with Trapped Head and & Yes \\
\hline Regularly Improving Neonatal Condition and & Yes* \\
\hline $\begin{array}{l}\text { Post-resuscitation Blood Gases with Substantial } \\
\text { Base Deficit }\end{array}$ & Yes \\
\hline
\end{tabular}

\section{Table}

Minimal criteria were necessary to establish cord occlusion with terminal fetal bradycardia as likely etiology of neonatal depression with normal or near-normal cord gases in the absence of widened umbilical venoarterial $\mathrm{pH}$ difference.

* If 1 minute Apgar score is 0 , regularly improving neonatal condition may not occur.
- $\quad$ Cord occlusion with terminal fetal bradycardia may occur in the absence of widened umbilical venoarterial $\mathrm{pH}$ difference, albeit this finding is unusual.

- A normal set of cord gases associated with a severely depressed newborn infant suggests cord occlusion with terminal fetal bradycardia.

- In order to establish cord compression with terminal fetal bradycardia as the likely etiology of neonatal depression, in the absence of a marked venoarterial $\mathrm{pH}$ difference, one must rigorously demonstrate:

o preceding evidence of a vulnerable cord

o the presence of normal or near-normal venous and arterial cord gases, and

o a post-resuscitation blood gas that has a much worse base deficit

\section{References:}

1. Barkley, C. I may be wrong, but I doubt it. New York, Random House; 2002.

2. White CR, Doherty DA, Henderson JJ, Kohan $R$, et al. Benefits of introducing universal umbilical cord blood gas and lactate analysis into an obstetric unit. Aust N Z J Obstet and Gynaecol 2010;50:318-28.

3. Myers RE. Experimental models of perinatal brain damage: Relevance to human pathology. In: Intrauterine asphyxia and the developing fetal brain. Gluck L [ed]. Year Book Publ Co, New York, 1977, pp37-97.

4. Vannucci RC. Mechanisms of perinatal hypoxic-ischemic brain damage. Semin Perinatol 1993;17:330-7.

5. Jopling J, Henry E, Wiedmeier SE, Christensen RD. Reference ranges for hematocrit and blood hemoglobin concentration during the neonatal period: Data from a multihospital health care system. Pediatrics 2009,123:e333-7.

6. Bear M. Personal communication, 2011.

7. Edwards AL. Experimental design in psychological research, 4th ed. New York, Holt Rinehart Winston; 1972, p274-5.

8. Levy H, Meier PR, Makowski EL. Umbilical cord prolapse. Obstet Gynecol 1984;64:499-502.

9. Usta IM, Mercer BM, Sibai BM. Current obstetrical practice and umbilical cord prolapse. Am J Perinatol 1999;16:479-84.

Disclosure: The author has no disclosures.

Key Points 


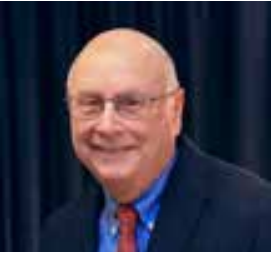

Jeffrey Pomerance, MD

Emeritus Professor of Pediatrics,

UCLA

Former Director of Neonatology,

Cedars-Sinai Medical Center, Los Angeles

Jeffrey Pomerance <jpomerance@msn.com>

\section{Readers can also follow NEONATOLOGY}

via our Twitter Feed @NEO

MedEd On The Go ${ }^{\circledR}$ presents

3 Accredited Education Programs in Short-Form Video Format

Available for CME/CNE Credits

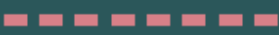

The Role of Nutrition \& Exclusive Human Milk for Very Low Birth Weight Infants

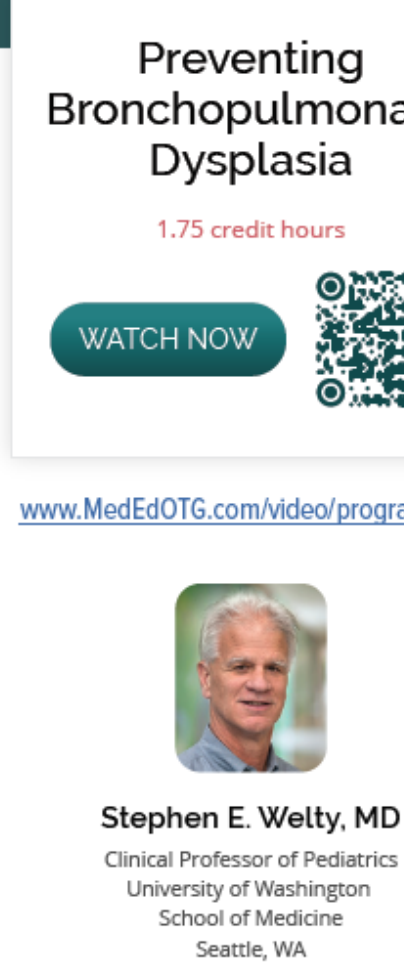

Preventing

Neonatal

Sepsis

0.5 credit hours

WATCH NOW

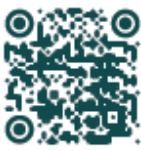

www.MedEdOTG.com/video/program/609

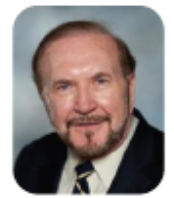

Dan L. Stewart, MD

Professor of Pediatrics \& International Pediatrics University of Louisville School of Medicine

Co-Director of NICU \& ECMO

Norton Children's Hospital Louisville, $\mathrm{KY}$

\section{Preventing \\ Retinopathy of Prematurity}

1.0 credit hour

\section{WATCH NOW}

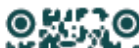

Oxys;

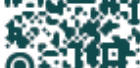

OFin:

www.MedEdOTG.com/video/program/608

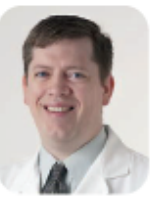

Jonathan R. Swanson, MD, MSc

Associate Professor of Pediatrics

University of Virginia

Children's Hospital

Charlottesville, VA 